\title{
CARVALHO, Laura. Valsa brasileira: do boom ao caos econômico. São Paulo: Todavia, 2018. 192 p.
}

\section{Cláudio César Foltran Ulbrich ${ }^{1}$}

Os governos de Luís Inácio Lula da Silva (2003-2010) e Dilma Rousseff (2010-2016), constituindo parte de um contínuo temporal e fazendo parte de um mesmo grupo político, o Partido dos Trabalhadores (PT), conformam um período de experimentações físcais que, em um período de pouco mais de uma década, foram do crescimento à contração. Herdando um país estagnado e às voltas com a inflação, os dois presidentes aplicaram políticas de incentivo e austeridade para tentar contornar a situação inusitada das décadas de 2000 e 2010, com variados graus de sucesso. Chama a atenção, no entanto, a transformação de uma matriz social-democrática, principalmente entre os anos 2006 e 2010, para um extremo conservadorismo fiscal, entre 2015 e 2016, que marcam o colapso do período petista com o impeachment da ex-presidente Dilma. Laura Carvalho, ao analisar essas transformações constrói, em Valsa Brasileira (2018), um panorama das políticas econômicas adotadas entre 2003 e 2016, lançando luz às escolhas e circunstâncias que, em cerca de uma década, levaram o Brasil de um crescimento sustentado a uma recessão profunda.

A autora, bem distante dos bastidores em que reside a maioria dos trabalhos de economistas, faz das suas análises propostas públicas

\footnotetext{
${ }^{1}$ Estudante do $7^{\circ}$ período do curso de História (Licenciatura e Bacharelado) na Universidade Federal do Paraná. Realiza Pesquisa Individual sob a orientação da Prof ${ }^{\mathrm{a}} \mathrm{Dr}^{\mathrm{a}}$ Andréa Carla Doré.
} 
para construir um novo modelo econômico de crescimento ao Brasil. Graduada em Ciências Econômicas pela Universidade Federal do Rio de Janeiro (UFRJ) em 2006, se especializou em Economia da Indústria e da Tecnologia em 2008, pela mesma universidade, e em macroeconomia pela New School of Social Research, onde estudou os possíveis caminhos para a retomada de crescimento econômico após períodos de recessão. Foi professora na Fundação Getúlio Vargas (FGV) entre 2012 e 2015, quando se tornou docente da Faculdade de Economia, Administração e Contabilidade da Universidade de São Paulo. Atualmente, contribui para o debate público através de suas colunas em jornais de grande circulação, como a Folha de São Paulo e o Nexo.

Como chave de análise econômica dos 13 anos que constituem o período petista, a autora apresenta a matriz fiscal como os três passos de uma valsa, que marcam três momentos distintos, alusivos às políticas levadas a cabo nesse período. O primeiro, "um passo à frente", representa o governo Lula II (2006-2010), articulando a distribuição de renda com o investimento público elevado. O segundo, "um passo ao lado", foi o governo Dilma I (2011-2014), com a adoção da "agenda Fiesp", denominada "Nova Matriz Econômica", com incentivos fiscais para o setor industrial. Por fim, o terceiro, "um passo atrás”, conforma o curto período do governo Dilma II (2015-2016), em que foram adotados políticas de austeridade e arrocho fiscal que, em última instância, representou o desmonte do frágil Estado de bem-estar social construído nas décadas anteriores (CARVALHO, 2018: 11-12). O livro é dividido em cinco capítulos distintos: os três primeiros descrevem 
respectivamente os três "passos de dança" da economia brasileira; o quarto traz uma análise global da situação nacional e de seus possíveis caminhos para superar as dificuldades, considerando as nossas especificidades econômicas; o quinto, um breve epílogo sobre a emergência do autoritarismo a partir do desgaste econômico que, no mundo todo, foi provocado pelas décadas sucessivas de austeridade.

No primeiro capítulo, “O Milagrinho brasileiro: um passo à frente", Carvalho analisa os oito anos do governo Lula da Silva, considerando, especificamente, a sua matriz econômica. Conforme investiga a autora, esse período foi marcado por guerras intestinas dentro do governo e do próprio Partido dos Trabalhadores, nas quais se opunham os que procuraram manter, num primeiro momento, as políticas herdadas de Fernando Henrique Cardoso (1995-2002), com baixas taxas básicas de juros e a busca por manutenção do superávit primário, e os que acreditavam na necessidade de uma maior ousadia fiscal. Essa política marcou o seu primeiro mandato (2003-2006), embora tenha mantido o baixo crescimento do PIB. Para demonstrar esses primeiros embates, a economista lança mão de reportagens e discursos que, embora apresentem in loco os desencontros nesse período, são usadas indistinta e acriticamente, sem considerar, por exemplo, os intuitos e silêncios nos discursos oficiais e as linhas editoriais dos diversos periódicos consultados.

Para Carvalho, foi apenas a partir do segundo governo que a matriz econômica foi alterada, focando, especificamente, em três aspectos: "a distribuição de renda da pirâmide, [...] maior acesso ao crédito e maiores investimentos públicos em infraestrutura física e 
social" (CARVALHO, 2018: 19). Esse período, denominado "Milagrinho", constituiu o "passo à frente", uma vez que foi marcado por sustentado crescimento econômico e distribuição de renda. É notório que, a despeito de colocar em dúvida a continuidade indefinida desse sistema, apresenta estes três sustentáculos como uma política bem-sucedida de inclusão e crescimento, sob uma luz extremamente positiva. Baseando-se em estudos na área econômica (uma diferença em relação à primeira parte), a autora argumenta que esse crescimento permitiu não só o incremento da renda média da população, mas o próprio consumo, uma tese já consolidada nos estudos recentes sobre o período. $^{2}$

No segundo capítulo, “A agenda Fiesp: um passo ao lado”, Laura Carvalho passa a analisar o incongruente período do governo Dilma, uma clivagem em relação ao governo anterior, a despeito de ser apontada como sua herdeira e sucessora direta. Mais ainda, é um período de intensas pressões políticas que a fizeram mudar radicalmente o rumo da economia brasileira, assumindo uma postura ortodoxa que, ao fim e ao cabo, sufocou o Milagrinho e fez o governo cair em uma espiral de austeridade e desregulação a partir de 2015. Segundo o histórico construído pela autora, a pressão do empresariado nacional levou à adoção de uma política fiscal rigorosa, contracionista, próxima ao "crescimento centrado nos desenvolvimentos industriais nos moldes

\footnotetext{
${ }^{2}$ Com efeito, Samuels (2004), Marques (2005) e Singer (2010) apontam essas duas "facetas" do governo Lula, apontando não apenas a virada no primeiro para o segundo mandato, numa mistura de pragmatismo com políticas sociais, mas também a própria manutenção das bases econômicas liberais, contraditórias ao discurso socialista dos primeiros anos do Partido dos Trabalhadores.
} 
asiático" (CARVALHO, 2018: 55). Como base, aponta os diversos manifestos de economistas que, a partir de jornais e colunas, propunham uma mudança na matriz econômica. Conclui, em retrospecto, que essa política não apenas não trouxe os resultados esperados, como acarretou a adoção de políticas cada vez mais ligadas ao neoliberalismo: incentivos fiscais, linhas de créditos às grandes empresas, o freio nos investimentos públicos estatais. Em última instância, isso provocou não apenas a deterioração fiscal, mas o aumento da dívida pública, que pautou, de 2015 em diante, uma política ainda mais radical.

O panorama desenvolvido pela economista termina no terceiro capítulo, "A panaceia fiscal: um passo atrás", o terceiro movimento, e talvez o mais significativo, dos treze anos ininterruptos do governo petista. As políticas de austeridade iniciais tomadas no primeiro mandato de Dilma, ainda marginais, se tornaram agressivamente presentes a partir de 2015, principalmente com a posse, no Ministério da Fazenda, de Joaquim Levy. A completa desestruturação dos dois elementos que constituíram o Milagrinho - as políticas de distribuição de renda e o PAC (Programa de Aceleração do Crescimento, que constituía financiamento público de obras de infraestrutura) - levou ao colapso de um modelo popular e sustentável da economia brasileira. Em especial, aponta a constante contradição nos discursos, mantendo a linha geral dos primeiros anos, com a política efetivamente aplicada, de estabelecimento de estímulos fiscais propostos pelo empresariado.

A falta de resultados, no entanto, com a estagnação do crescimento (embora a então presidente tenha aplicado à risca o receituário liberal), levou à criação de uma panaceia de todos os 
problemas: o impeachment. Apontada como a culpada pela estagnação, Rousseff foi derrubada pelo grande empresariado, articulado em torno da Fiesp, que explorou o peso político das "pedaladas fiscais", uma vez que essas recaíam em uma das práticas vedadas pela Lei da Responsabilidade Fiscal. O resultado foi o colapso da era petista e a ascensão de Michel Temer (MDB), que assumiu de peito aberto o programa liberal por meio da então denominada "Ponte para o Futuro". Objeto de análise por diversos campos, entre eles a Economia, a História e o Jornalismo, o fim melancólico de Dilma Rousseff é em geral apontado como fruto de políticas econômicas equivocadas somadas a uma intensa intriga palaciana, na qual a presidente foi considerada um entrave à adoção de políticas econômicas mais ortodoxas. À semelhança de Carvalho, diferentes autores buscam dramatizar esses dois anos de inflexão na política brasileira, como é o caso da economista Monica de Bolle (2016), com a crônica Como matar a borboleta azul, e da cineasta Petra Costa (2019), com o documentário Democracia em Vertigem.

A análise da autora se consolida nos dois últimos capítulos, em que, a partir do panorama construído nos três capítulos anteriores, busca estabelecer como criar uma economia que fuja da frágil ortodoxia liberal sem, entretanto, necessitar das circunstâncias que tornaram o Milagrinho possível. Em “Acertando os passos”, Laura Carvalho propõe que a matriz econômica adotada a partir de 2015 foi um "tiro no pé" por parte do empresariado, que nem de longe teve os retornos esperados. Propõe, portanto, a retomada dos elementos que, anteriormente, garantiram alguma inclusão social pelas políticas de Estado: o fim da 
austeridade, a retomada dos investimentos públicos, a reestruturação do Estado de bem-estar social, uma reforma tributária progressiva e o controle da taxa de juros.

O último capítulo, "Dançando com o Diabo", é sintomático não apenas do momento em que a autora escreve, mas de seus propósitos políticos no que assumira vocalmente desde então. Não apenas ela aponta uma conformidade entre as políticas de austeridade e o aumento de tendências sociais autoritárias e populistas, um reflexo evidente nas eleições de 2018 (que, embora não seja citada diretamente, por certo influenciou a escrita de seu estudo), quanto propõe que um caminho democrático se dá pela inclusão e estabilidade dentro de um crescimento sustentado. Não à toa, muitas de suas políticas serviram de base para a construção das propostas políticas de Guilherme Boulos (PSOL), um dos candidatos mais à esquerda na eleição de 2018, da qual ela participou diretamente como consultora (NSC TOTAL NOTÍCIAS DE SANTA CATARINA, 2018). Longe de ser um folhetim político, no entanto, Valsa Brasileira é um estudo do corolário de diferentes políticas econômicas que passaram do caráter popular ao de cópia do receituário liberal - levando, em última instância, ao colapso fiscal brasileiro em apenas três anos; assim como apresenta o desenrolar de uma nova perspectiva, heterodoxa, para a reconstrução do país no médio e longo prazo.

\section{Bibliografia}


ACTIS, Esteban. Del condominio a la dicotomía: las relaciones entre los gobiernos del PT en Brasil con el empresariado internacionalizado brasileño (2003-2016). Polis - Revista Latinoamericana, Santiago (Chile), n. 48, p. 175-199, 2017.

BRESSER-PEREIRA, Luiz Carlos. O governo Dilma frente ao "tripé macroeconômico" e à direita liberal e dependente. Novos Estudos, São Paulo, v. 32, n. 1, p. 5-14, mar. 2013.

CARVALHO, Laura. Valsa brasileira: do boom ao caos econômico. São Paulo: Todavia, 2018.

CURADO, Marcelo. Por que o governo Dilma não pode ser classificado como novo-desenvolvimentista?. Revista de Economia Política, São Paulo, v. 37, n. 1, p. 130-146, jan./mar. 2017.

DE BOLLE, Monica Baumgarten. Como matar a borboleta-azul: uma crônica da era Dilma. São Paulo: Intrínseca, 2016.

DEMOCRACIA em Vertigem. Direção: Petra Costa. Produção: Joanna Natasegara; Shane Boris; Tiago Pavan. Netflix, 2019. 1 vídeo (121 min). Disponível em: <https://www.netflix.com/br/title/80190535>. Acesso em: 24 set. 2020.

GURU econômico de Boulos, Laura Carvalho defende diminuir desigualdade como base do crescimento. NSC - Notícias de Santa Catarina, Florianópolis, 05 mai. 2018. Disponível em: $<$ https://www.nsctotal.com.br/noticias/guru-economico-de-boulos-laura -carvalho-defende-diminuir-desigualdade-como-base-do $>$. Acesso em: 24 set. 2020.

MARQUES, Luiz. Governo Lula: social-liberal ou social-reformista?. Porto Alegre: Veraz, 2005.

SAMUELS, David. From Socialism to Social-democracy: party organization and the transformation of the Worker's Party in Brazil. Comparative Political Studies, v. 37, n. 9, p. 999-1024, nov. 2004.

SINGER, André. A segunda alma do Partido dos Trabalhadores. Novos Estudos, São Paulo, v. 29, n. 3, p. 89-111, nov. 2010. 
Cadernos de Clio, Curitiba, v. 9, nº. 2, 2018

Recebido em: 24/09/2020

Aceito em: 23/10/2020 